\title{
The Neuropathic Bladder in Children with Spinal Cord Injury
}

\author{
F. Fanciullacci, MD, A. Zanollo, MD, S. Sandri, MD, and F. Catanzaro \\ MD \\ Urologic Department, Section for Myelolesions; Hospital of Magenta, Milan, Italy.
}

\section{Summary}

The occurrence of spinal cord lesions in children has been reported to be rare. In the literature, there is little information about the management of the neurovesical dysfunction. We report our experience in the treatment of the neuropathic bladder in 18 children with spinal cord injury. The long-term follow-up shows that there is a good recovery and the complication rate is low.

Key words: Spinal cord injury in children; Neuropathic bladder in children.

The incidence of post-traumatic myelolesions varies from 1.3 to $2 \cdot 7$ per 100000 inhabitants (Tricot 1981). In children it is lower, ranging from less than $1 \%$ to $3.3 \%$ of all patients with post-traumatic myelolesion (Melzak, 1969; Audic and Maury, 1969; Burke, 1971). Another study on the epidemiological features of acute spinal cord lesions in a pediatric population gives an incidence of $9.4 \%$ of all cases of spinal cord injury (SCI) in 18 counties of California in 1970 and 1971 (Kewalramani et al., 1980).

There are few reports about urinary bladder recovery in children with SCI. As is reported by Bedbrook (1981), the life expectancy of the younger patients is not possible to estimate, for few have been managed collectively in spinal units. No spinal unit has amassed enough patients to assess the acute or the long-term prognosis.

In our Unit, we have studied a series of 18 children with spinal cord injury. The aim of this paper is to relate our experience in the treatment of the neuropathic bladder in SCI children and the urological balance in a long-term followup.

\section{Materials and methods}

From 1972 to 1985, we observed 18 children with SCI (16 males and 2 females) out of 433 patients with post-traumatic paraplegia $(3.6 \%)$. The mean age when 
Table I 18 children with spinal cord injury. * General data

\begin{tabular}{lccccc}
\hline $\begin{array}{c}\text { Mean age at } \\
\text { the accident }\end{array}$ & $\begin{array}{c}\text { Cervical } \\
\text { lesion }\end{array}$ & $\begin{array}{c}\text { Thoracic } \\
\text { lesion }\end{array}$ & $\begin{array}{c}\text { Lumbar } \\
\text { lesion }\end{array}$ & $\begin{array}{c}\text { Complete } \\
\text { lesion }\end{array}$ & $\begin{array}{c}\text { Evidence of } \\
\text { fracture of the } \\
\text { spine }\end{array}$ \\
\hline $5 \cdot 7$ years $^{\star}$ & 2 & 8 & 8 & 13 & 10 \\
\hline
\end{tabular}

$\star 3.6 \%$ of all post-traumatic myelolesions observed in the same period.

$\star \star 9$ had myelolesions before the age of 5 years.

Table II Urological data at the initial evaluation in 18 children with SCI (from 2 months to 1.5 years after trauma)

\begin{tabular}{ll}
\hline Upper Urinary Tract & - Normal in 13 patients \\
& - Slight dilatation in 2 \\
& - Vesico-ureteral reflux in 2 (in 1 ureteral stone) \\
& - Renal stone in 1 patient \\
& - Present in $15 / 18$ patients $\left(83^{\circ}{ }_{o}\right)$ \\
Urinary Tract Infection $\star$ & \\
Fourteen patients had a residue of less than $20^{\circ}{ }_{o}$ of the bladder capacity (balanced bladder)
\end{tabular}

^ In 13 asymptomatic bacteriuria.

the accident happened was 5.7 years. Nine children had the myelolesion before the age of 5 years. Two had cervical lesions, 8 thoracic and 8 lumbar. Eleven of the patients had car accidents $(61 \%), 3$ domestic accidents, 1 birth trauma and 1 scoliosis (in this case, paraplegia appeared after an operation). For 2 children the origin of the trauma was not evaluated. Ten children out of 18 had evidence of fractures or dislocation of the vertebral bodies and 13 had complete lesions (general data are reported in Table I).

The neurourologic approach does not differ very much from that in adults. We have to consider the functional aspects of the bladder in the paediatric age (small vesical capacity, presence of uninhibited contraction ...) and we try to limit radiological investigations, preferring echography and radioisotope renography. Urodynamic investigation maintains its importance in defining the behaviour of the detrusor and its relation to the sphincter.

Almost all the children were decatheterised quite early (9 within 2 months and 5 within 4 months). Only one patient has an indwelling catheter for 1 year. In 3 children, the period of catheterisation was not evaluated. The management was conservative and consisted of manoeuvres for bladder emptying and intermittent catheterisation (IC) to help the bladder to recover. We kept a chart of the time and quantities of micturition, urine leakage and residue. The number of IC was progressively reduced as micturition reappeared and the residue was lowered.

In the follow-up, we checked the upper urinary tract (UUT) condition, urinary tract infection (UTI) rate and the detrusor/sphincter balance.

\section{Results}

Generally the bladder recovered its emptying quite easily. Spinal shock was shorter in those with upper motor neuron lesions compared to the 4-6 week 
Table III Urodynamic data

\begin{tabular}{ll}
\hline-12 hyperreflexia & 6 bladder/sphincter dyssinergia \\
& 6 not evaluated \\
-3 areflexia with denervation of the & \\
perineal floor & \\
-3 not evaluated & \\
\hline
\end{tabular}

Table IV Follow-up of the conservative management of the neuropathic bladder in 14 children with SCI (mean $7 \cdot 7$ years -6 children more than 11 years)

\begin{tabular}{ll}
\hline Upper Urinary Tract ${ }^{\star}$ & - Normal in $8 / 11$ patients \\
& - Slight dilatation in 1 \\
& - Vesico-ureteral reflux in 2 (with normal IVP) \\
Urinary Tract Infection $\star \star$ & - Present in $7 / 14$ patients $(50 \%)$ \\
Twelve patients had a residue of less than $20^{\circ}{ }_{0}$ of the bladder capacity (balanced bladder) \\
\hline$\star 11 / 14$ were investigated about their UUT by urography or radioisotope renography. \\
$\star \star \star$ in 5 asymptomatic bacteriuria.
\end{tabular}

period seen in adults. All the patients had radiourological investigations and 15 had urodynamic studies. The following data refer to the initial evaluation, following spinal shock (from 2 months to 1.5 years after the trauma) (Tables II and III).

The 2 children with stones were operated on. One of the 2 patients with reflux later developed a urethrocele and vesical stones (he had had an indwelling catheter for 1 year). Incontinence was not diagnosed until the child was 5 years old. In any case, continence was partial in all cases. Pharmacotherapy has been of secondary importance: only 2 children were given oxybutynin + IC, in 1 case for initial ureteroidronephrosis and in the other to try to obtain good continence (female, 6 years old).

Follow-up: this has been carried out in 14 children (mean time for the trauma 7.7 years; $\min 2$ years, $\max 16$ years). The relevant data concerning the followup studies are given in Table IV. The 2 children who had reflux, have a UUT in good conditions, as shown by IVP. Of the 3 children where the condition of their UUT was not checked, 2 are free of UTI, 1 has asymptomatic bacteriuria and 2 have no residue. The UUT of the boy managed by IC + oxybutynin, because of initial ureteroidronephrosis, improved. For all the children, the control of urinary continence is a problem. UTI was generally asymptomatic except for 2 children. Six children have had a follow-up for more than 11 years.

\section{Discussion}

There are few reports concerning neuropathic bladder recovery in SCI children. According to Audic (1981) it seems that there are fewer complications in the urinary apparatus in children than in adults. The manoeuvres for bladder emptying, and, if necessary, IC maintain their usefulness (Audic, 1981). Cass (1984) reports the management of the neuropathic bladder in 413 children, 47 of whom had SCI, but he does not differentiate between the treatment and the 
complication rate between SCI patients and that in children with myelomeningocele.

We did not see all the children in the acute phase, but almost all were decatheterised quite early. For all the patients, a conservative management was adopted. The recovery from spinal shock was shorter than that seen in adults.

Our children obtained a good balance of their neuropathic bladders, as shown by the low rate of symptomatic UTI, the good emptying of the bladder and the quite good conditions of the UUT in the long-term follow-up, (6 children for more than 11 years). The early decatheterisation may have assisted the recovery. From out data, it seems possible to conclude that the prognosis for the neuropathic bladder in SCI children is good, and urinary tract complications are uncommon.

\section{References}

Audic B, and MAury J 1969 Secondary Vertebral Deformities in Childhood and Adolescence. Paraplegia 7:10-16.

Audic B 1981 La Paraplegie ed. by Marc Maury; Flammarion Medicine-Sciences, Paris pp. 685688.

BEDBROOK GM 1981 The Care and Management of Spinal Cord Injuries, Springer-Verlag, New York, Heidelberg, Berlin, pp. 238-239.

BURKe D 1971 Spinal Cord Trauma in Children. Paraplegia 9:1-14.

CAss AS, Luxenberg M, Johnson CF, Gleich P 1984 Management of the Neurogenic Bladder in 413 Children. Fournal of Urology 132: 521-525.

Kewalramani LS, Kraus JF, Sterling HM 1980 Acute Spinal Cord Lesions in a Pediatric Population: Epidemiological and Clinical Features. Paraplegia 18: 206-219.

MelzaK J 1969 Paraplegia among Children. Lancet ii: 54-48.

Tricot A 1981 La Paraplegie ed. by Marc Maury; Flammarion Medicine-Sciences, Paris, p. 3. 